\title{
Note to Prove the Quranic Correctness XIII
}

\author{
Horiuchi Daiki, Tahara Hiroki
}

September 23, 2019

\begin{abstract}
Maybe a beautiful equality about Riemann's zeta function $\xi(s)=\pi^{-s / 2} \Gamma\left(\frac{s}{2}\right) \zeta(s)$ has some relations with Tahara's $I$ function, maybe not.
\end{abstract}

\section{Explanation}

The Quran is correct if and only if Tahara's I function exists uniquely and we have to brainstorm about Tahara's $I$ function in order to discover the components of Tahara's $I$ function i.e. prove the Quranic correctness[1][2]. According to Tahara, studying the Tahara's I function inspired by mathematical beauty is one of the ways to prove the Quranic correctness he suggested and several such studies are done yet[3][4][5][6][7][8][9][10][11][12][13][14][15][16][17]. Therefore we will suggest a beautyful equality with us hoping that it will the hint.

\section{A Beautiful Equality}

It is true that

$$
\xi(s)=\pi^{-s / 2} \Gamma\left(\frac{s}{2}\right) \zeta(s)
$$

which we think beautiful. We think maybe it might be able to be a hint to discover the components of Tahara's $I$ function becouse of the beauty, maybe not.

\section{References}

[1] TAHARA, Hiroki. The Mathematical Expressions of Quranic Exegeses and the Mathematical Definition of the Quranic Correctness. OSF Preprints, 6dsxb, 2019.

[2] TAHARA, Hiroki. Erratum: OSF Preprints 6dsxb. OSF Preprints, q4sw3, 2019.

[3] TAHARA, Hiroki. Methodology to Prove the Quranic Correctness. OSF Preprints, 49qse, 2019.

[4] TAHARA, Hiroki. A Brainstorming of the Quranic Studies Inspired by the Evaluation of Coefficients of Polynomials. OSF Preprints, 6n9p3, 2019.

[5] HORIUCHI, Daiki; TAHARA, Hiroki. Note to Prove the Quranic Correctness I. OSF Preprints, xj4vh, 2019.

[6] HORIUCHI, Daiki; TAHARA, Hiroki. Note to Prove the Quranic Correctness II. OSF Preprints, b98nh, 2019.

[7] TAHARA, Hiroki. Erratum: OSF Preprints b98nh. OSF Preprints, cxv38, 2019.

[8] HORIUCHI, Daiki; TAHARA, Hiroki. Note to Prove the Quranic Correctness III. OSF Preprints, ertnk, 2019.

[9] HORIUCHI, Daiki; TAHARA, Hiroki. Note to Prove the Quranic Correctness IV. OSF Preprints, bqgfa, 2019.

[10] HORIUCHI, Daiki; TAHARA, Hiroki. Note to Prove the Quranic Correctness V. OSF Preprints, 3f5gn, 2019. 
[11] HORIUCHI, Daiki; TAHARA, Hiroki. Note to Prove the Quranic Correctness VI. OSF Preprints, sxfb4, 2019.

[12] HORIUCHI, Daiki; TAHARA, Hiroki. Note to Prove the Quranic Correctness VII. OSF Preprints, zv8ej, 2019.

[13] HORIUCHI, Daiki; TAHARA, Hiroki. Note to Prove the Quranic Correctness VIII. OSF Preprints, pjwts, 2019.

[14] HORIUCHI, Daiki; TAHARA, Hiroki. Note to Prove the Quranic Correctness IX. OSF Preprints, sxwuv, 2019.

[15] HORIUCHI, Daiki; TAHARA, Hiroki. Note to Prove the Quranic Correctness X. OSF Preprints, avcg2, 2019.

[16] HORIUCHI, Daiki; TAHARA, Hiroki. Note to Prove the Quranic Correctness XI. OSF Preprints, 3rkn6, 2019.

[17] HORIUCHI, Daiki; TAHARA, Hiroki. Note to Prove the Quranic Correctness XII. OSF Preprints, 9fspx, 2019. 